\title{
O LAZER DOS FERROVIÁRIOS EM RIO CLARO-SP E O CONTROLE DA COMPANHIA PAULISTA ${ }^{1}$
}

Recebido em: 08/09/2017

Aceito em: 10/04/2018

\author{
Renan Vidal Mina ${ }^{2}$ \\ Universidade Federal de São Carlos \\ São Carlos - SP - Brasil \\ Marco Antônio Bettine de Almeida ${ }^{3}$ \\ Universidade de São Paulo \\ São Paulo - SP - Brasil
}

RESUMO: Este artigo aborda dois pontos principais: i) as atividades de lazer dos trabalhadores da Companhia Paulista de Estradas de Ferro em Rio Claro; ii) e a estratégia da empresa em prolongar o controle sobre seus funcionários até mesmo nos momentos de não trabalho, a partir da criação do Grêmio Recreativo da Paulista. A chegada dos trilhos e a instalação das oficinas da companhia ferroviária impulsionaram a formação da classe operária local, criando as bases para a emergência dos espaços de sociabilidade frequentados por esses trabalhadores. $O$ desfrute do lazer pelos ferroviários, além de possibilitar o distanciamento momentâneo da extenuante rotina de trabalho, contribuía para o fortalecimento dos laços do grupo. A direção da Paulista, disposta a vigiar as ações de seus funcionários fora do universo fabril, empenhou-se em reger suas opções de lazer, fundando um clube social e recreativo destinado aos ferroviários.

PAlavras ChaVe: Atividades de Lazer. Ferroviários. Companhia Paulista de Estradas de Ferro.

\section{THE LEISURE OF RAILWAY LABOURERS IN RIO CLARO-SP AND THE CONTROL OF THE COMPANHIA PAULISTA}

ABSTRACT: This article addresses two main points: i) the leisure activities of the labourers of Companhia Paulista Railways in Rio Claro; ii) and the company's strategy

\footnotetext{
${ }^{1}$ Este artigo é fruto do trabalho desenvolvido na Dissertação de Mestrado de Renan Vidal Mina, cujo título é "A bola e os trilhos: a incorporação do futebol em Rio Claro e o desenvolvimento do Rio Claro Futebol Clube", defendida no Programa de Pós-Graduação em Mudança Social e Participação Política da Universidade de São Paulo, contando com apoio da CAPES.

${ }^{2}$ Bacharel em Geografia pela Universidade Federal de Alfenas. Mestre em Ciências pelo Programa de Pós-Graduação em Mudança Social e Participação Política da Universidade de São Paulo. Doutorando em Sociologia na Universidade Federal de São Carlos.

${ }^{3}$ Doutor em Sociologia do Lazer pela Unicamp. Pós-Doutor em Sociologia do Esporte pela Universidade do Porto. Professor Associado da Escola de Artes, Ciências e Humanidades da Universidade de São Paulo.
} 
to extend control over its employees even in non-work moments, since the creation of Grêmio Recreativo of Paulista. The arrival of the rails and the installation of the workshops of the railway company stimulated the formation of the local working class, creating the bases for the emergence of the spaces of sociability frequented by these labourers. The enjoyment of leisure by the railway labourers, besides allowing the temporary distance from the exhausting work routine, contributed to the strengthening of the group's ties. The management of Paulista, willing to oversee the actions of its employees outside the factory universe, committed itself to governing its leisure options, founding a social and recreational club for the railway labourers.

KEYWORDS: Leisure Activities. Railway labourers. Companhia Paulista Railways.

\section{Introdução}

Os ferroviários em todo o mundo são vistos como um setor diferenciado da classe trabalhadora, seja pela dignidade dos seus uniformes, pela relação com a máquina e a velocidade materializadas na figura do maquinista ou pela consolidação de núcleos de habitação claramente configurados em diversas cidades (LANNA, 2016, p. 506).

No Estado de São Paulo, o surto ferroviário foi gestado no interior da efervescente economia cafeeira no final do século XIX. O avanço das linhas férreas pelo Oeste Paulista ${ }^{4}$ expressou uma grande mudança na organização produtiva do café, introduzindo novas tecnologias, impondo novos agentes produtivos e criando novas relações de produção. Elas aceleraram o processo de aprimoramento na mecânica e metalurgia, ocasionando importantes transformações na forma de organização capitalista da produção, sobretudo nos serviços prestados pelas oficinas mecânicas que se desenvolveram junto ao complexo ferroviário.

Podemos dizer que a Companhia Paulista de Estradas de Ferro foi o primeiro grande núcleo de trabalho assalariado da cidade de Rio Claro. No interior de suas oficinas ou nos bairros que se constituíam ao redor dos trilhos, havia um expressivo

\footnotetext{
${ }^{4}$ Região que se define a partir de Campinas e segue em várias direções: Rio Claro, Limeira, São Carlos, Jaú, Piracicaba, Mogi-Mirim, Ribeirão Preto, entre outras.
} 
número de ferroviários em constante interação. Valores, costumes, hábitos e práticas se misturavam. Era um processo de formação cultural dos trabalhadores, buscando criar espaços específicos de sociabilização e trocar experiências com seus "semelhantes".

Para lidar com a emergente classe operária, a administração da Companhia Paulista pautou-se em uma estratégia de controle que ultrapassava os limites de suas oficinas, ou seja, foram desenvolvidos mecanismos de disciplinamento que se estendiam até o lazer dos ferroviários. Conforme discute Corbin (1995, p. 369), os capitalistas preocupavam-se com as ações dos operários inclusive fora do universo fabril, pois consideravam que estes últimos seriam propensos a lazeres mais degradantes, nocivos. Caberia aos patrões, portanto, criar e organizar esse lazer, pois essa seria a única maneira de afastar o proletariado da imoralidade.

Nesse sentido, discutiremos no presente artigo: i) as atividades de lazer dos trabalhadores da Companhia Paulista de Estradas de Ferro em Rio Claro; ii) e a estratégia da referida empresa em prolongar o controle sobre seus funcionários até mesmo nos momentos de não trabalho, a partir da criação do Grêmio Recreativo da Paulista.

\section{Primórdios do Lazer em Rio Claro-SP}

Importante ressaltar que as primeiras opções de lazer em Rio Claro surgem antes mesmo da formação da categoria dos ferroviários. Em meados das décadas de 1860 e 1870, já era possível notar grandes fazendeiros do Oeste Paulista expressando não só um significativo poderio financeiro, mas também um enorme desejo de livrar o país do atraso, das heranças do período colonial e imperial. Entre as formas encontradas pela elite fundiária para materializar o anseio pelo progresso estavam os investimentos 
direcionados à modernização das cidades, procurando dotá-las de elementos que reproduzissem o conforto dos principais centros europeus.

Os cafeicultores preocuparam-se em definir condutas que simbolizassem a maneira "correta" de viver, pensar, agir e sentir. Considerados sofisticados, os estilos europeizados de comportamento e convívio social foram sendo progressivamente importados. A cidade de Paris, reconhecida como a capital da cultura, dos prazeres e daqueles que podiam desfrutar o tempo livre, era a referência predileta destes indivíduos abastados que buscavam se desprender da imagem de senhores de escravos. Os modismos parisienses serviram de grande inspiração para os fazendeiros paulistas erigirem seus espaços de convivência e diversão. Adquirir o hábito de frequentar teatros, cinemas, cafés, restaurantes e clubes sociais, passou a ser uma forma de reproduzir os requintes da sociabilidade europeia.

Ao conquistarem um status econômico privilegiado, os fazendeiros de Rio Claro puderam atuar de forma mais intensa na estruturação do urbano. As parentelas Paes de Barros, Pacheco Jordão, Vergueiro, Negreiros, entre outras, foram algumas figuras ligadas à cafeicultura que estiveram à frente das reformas urbanísticas e da criação dos primeiros ambientes destinados à cultura e ao lazer, como o teatro São João (inaugurado em 1864), a sociedade recreativa Philarmonica (inaugurada em 1879) - destinada aos saraus dançantes, musicais e literários - e o Gabinete de Leitura (fundado em 1876).

Esses espaços, contudo, estavam restritos às famílias abastadas. O lazer daqueles que eram desprovidos de maiores posses limitava-se, a princípio, às festas e celebrações religiosas. O que será discutido ao longo do artigo é que a crescente complexidade da economia e da sociedade a partir da cafeicultura também dará base para a diversificação dos lugares de encontro e convívio entre os sujeitos. A vida social estende-se no sentido 
da busca cada vez mais constante das ruas e praças, dos passeios e encontros na esfera pública. Um dos grandes motores dessa mudança é a chegada dos trilhos da Companhia Paulista, que foram impulsionadores do processo de formação da classe operária local. Os ferroviários passaram a criar seus próprios espaços de sociabilidade, tentando - pelo menos de forma momentânea - se livrar das amarras do capital e se realizarem enquanto sujeitos.

\section{A Formação da Categoria dos Ferroviários}

O desenvolvimento econômico do "Oeste Paulista" a partir da cafeicultura proporcionou investimentos que resultaram no crescimento vertiginoso de diversas cidades no Estado de São Paulo. Como vimos, além da importação dos modelos europeus de sociabilidade, a arrancada do café veio acompanhada das estradas de ferro, estabelecidas justamente para atender a expansão da commodity. A implantação das linhas e ramais, somada ao abandono do trabalho escravo, viabilizaram a entrada de migrantes nacionais e estrangeiros no interior paulista.

Os caminhos de ferro não só facilitaram a chegada da mão-de-obra para as propriedades de café, mas também fomentaram o processo de urbanização de Rio Claro, propiciando um adensamento populacional em torno de atividades correlatas, como depósitos e comércio de materiais para a ferrovia, como carvão, lubrificantes e equipamentos, comércio de alimentos para os trabalhadores ferroviários, entre outros. Sem contar o estímulo para o desenvolvimento da indústria de material de transportes, a partir da instalação das oficinas de montagem e reparo de locomotivas, carros e vagões da Companhia Paulista (Figura 1), verdadeiros estabelecimentos industriais que além de 
permitir a obtenção de tecnologia de sua produção, eram importantes núcleos formadores de mão-de-obra especializada.

Figura 1: Interior das oficinas da Companhia Paulista de Estradas de Ferro em Rio Claro-SP, década de 1930

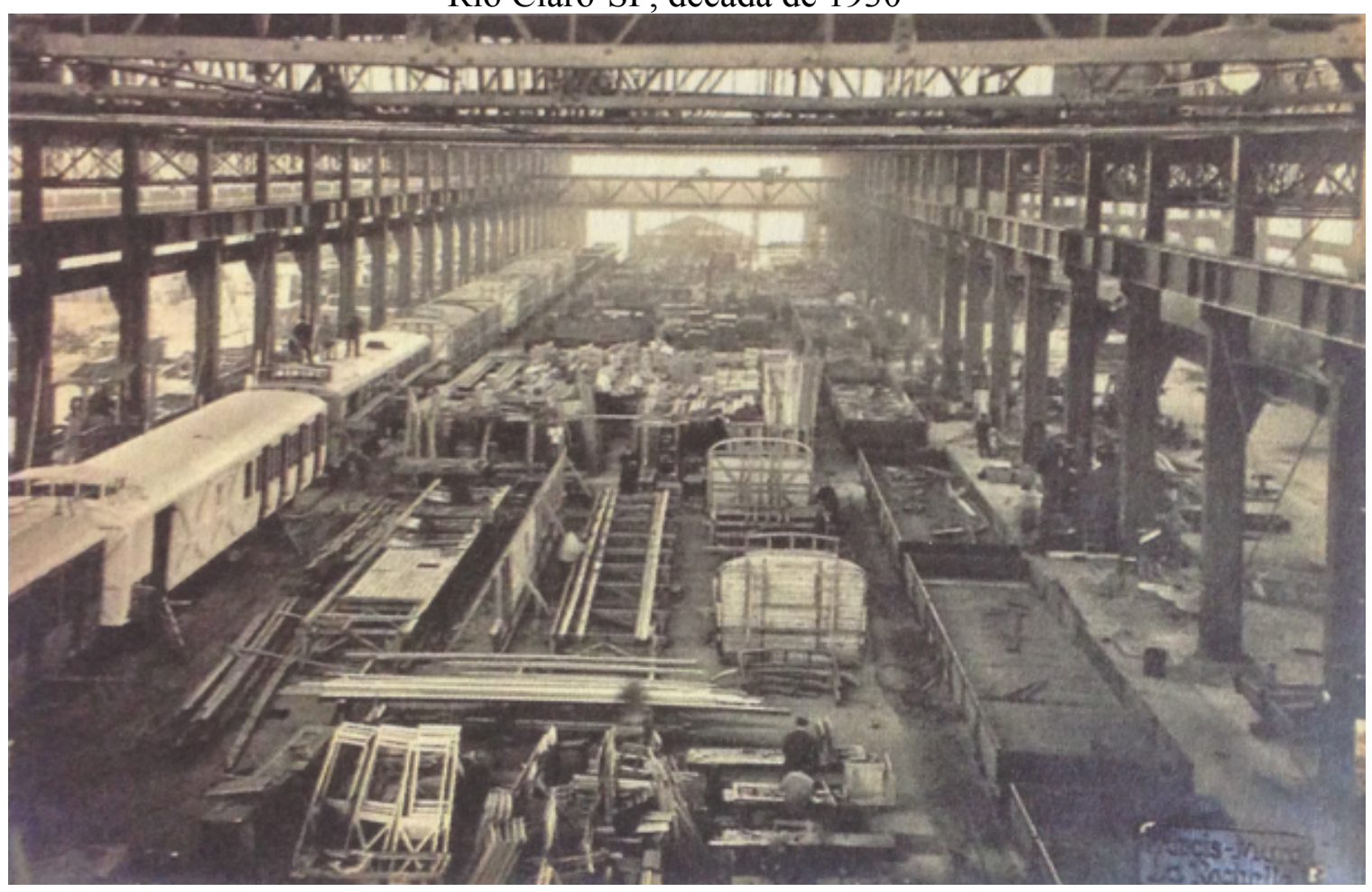

Fonte: Arquivo Público do Estado de São Paulo (2015, p. 16).

A companhia demandava um grande contingente de trabalhadores, seja para atuar na manutenção das linhas férreas, no carregamento e descarregamento de mercadorias na estação ou nos serviços mais pesados no interior das oficinas. Consequentemente, muitos de seus funcionários eram provenientes da capital do Estado, de diferentes regiões do país ou até mesmo do exterior. Suas residências agrupavam-se em torno dos trilhos, constituindo pequenos bairros e vilas operárias. Esses sujeitos cruzavam-se diariamente, se olhavam, interagiam, seus costumes, linguagens e gestos se misturavam. O sincretismo cultural era uma novidade tão impactante quanto às máquinas a vapor que propiciavam esses encontros. 
[...] Cidade Nova, Vila Operária, Vila Paulista, Vila Alemã, todos esses núcleos foram montados em torno das oficinas da Companhia Paulista de Estradas de Ferro. Eram mais ou menos 2.600 famílias que estavam ao redor da oficina de Rio Claro (GARCIA, 1992, p. 32).

Dentro da empresa ferroviária, as funções e atividades eram divididas sistematicamente. Na construção ou manutenção das linhas, estavam os trabalhadores de menor qualificação. Havia também marceneiros, carpinteiros, pintores, soldadores, ferreiros e ajustadores. Trabalhavam em média doze horas por dia, sem remuneração de hora extra e com apenas uma folga semanal, para colocar nos trilhos as locomotivas que seriam conduzidas por maquinistas e foguistas, com bilheteiros e bagageiros. Tudo sob a supervisão de engenheiros, mestres, chefes e inspetores, legitimados pelo maior conhecimento técnico e também pelo fato de serem representantes da administração geral da companhia (GARCIA, 1992, p. 111). Nos escritórios, centenas de almoxarifes, escriturários e contadores faziam as contas de tarifas, custos e fretes de mercadorias e milhares de passageiros que circulavam pelas composições de trens (LANNA, 2016, p. $520)$.

A obrigatoriedade de montar e consertar as locomotivas e vagões, ou de fazer o trem correr na hora certa, a qualquer custo, exigia muitas vezes o impensável dos trabalhadores, que se desdobravam e se solidarizavam para cumprir as tarefas. As oficinas ferroviárias quase sempre requisitavam tempo integral e preocupação constante por parte de seus operários, transformando-lhes em verdadeiros "escravos do seu ganhapão". Seus passos eram vigiados e cerceados, "havia o regulamento que estabelecia procedimentos, normas e punições para tudo" (CAMPOS, 2012, p.127). A descrição abaixo apresenta mais detalhes sobre o rigoroso cotidiano dos operários da Companhia Paulista em Rio Claro: 
O tempo de trabalho necessário para a sobrevivência ultrapassava, e muito, às duzentas horas mensais obrigatórias, que resultava em jornada mínima de oito horas, incluindo o sábado. Isso se não houvesse feriado no mês, pois, nesse caso, às oito horas desse dia, não trabalhado, seriam distribuídas ao longo do mês, para completar as duzentas horas. As horas extras pareciam já estar incorporadas no cotidiano (...). E em algumas ocasiões, o trabalhador roubava, também, algumas horas do sono necessário ao repouso diário (TENCA, 2006, p. 309).

\section{Ferroviários e Lazer: A Criação do Grêmio e o Controle da Companhia Paulista}

Se por um lado os operários tinham que lidar com as fortes cobranças no interior das oficinas da Paulista, de outro, cabe ressaltar que a convivência diária, os conhecimentos, as histórias, as lembranças, os segredos, as críticas à administração, as expectativas em relação ao futuro profissional, enfim, tudo o que se compartilhava no espaço de trabalho, fortalecia os laços afetivos e forjava uma identidade comum para os ferroviários. Nas palavras de Benévolo (1953, p. 45), os “railmen” constituíam uma só família, muito mais unida que as famílias operárias das grandes indústrias.

A concentração dos empregados da Paulista nas cercanias das linhas férreas e a própria proximidade entre eles no dia a dia da empresa ferroviária parecem ter auxiliado na difusão dos espaços voltados ao lazer operário. É nesse momento em que as cidades estão entrecortadas pelas linhas férreas que se criam os lugares de convivência coletiva, como os clubes sociais e recreativos. Os espaços de sociabilização surgem dessas necessidades de interação entre os "iguais", uma vez que a cidade se torna cada vez mais complexa com a crescente chegada de pessoas e a emergência de novas formas de pensar. É nessa convivência entre indivíduos com modos de vida em comum que se estruturam os laços de identidade.

As experiências organizativas possibilitavam a interação entre os sujeitos e o distanciamento momentâneo dos subalternos da extenuante rotina de trabalho. 
Transitando pelas ruas dos bairros, vilas operárias e no interior das oficinas ferroviárias, estas experiências refletiam uma classe trabalhadora interpretando e redimensionando, dentro dos estreitos limites possíveis, suas condições de existência. Tanto o local de residência quanto o de trabalho possuíam importância e significado como espaços de criação e recriação de cultura dos trabalhadores.

É no local de moradia, nas associações reivindicatórias e agremiações recreativas, nas praças, esquinas e bares, na rua e na casa que transcorre este vasto processo dinâmico de formação cultural, tornando o mundo denso de significados nem fixos, nem finais, nem únicos. Sempre renovados, esses significados são inventados ou reinterpretados apelando-se para as novas experiências ou para antigas tradições. E é aí que a heterogeneidade econômica, do ponto de vista dos lugares que ocupam no processo produtivo, cede lugar às múltiplas práticas cotidianas das classes populares, à troca de experiência de subalternos, aos múltiplos modos de oferecer resistência à dominação, à construção de uma identidade social mais ampla do que a da classe operária (ZALUAR, 1985, p. 50).

Os espaços de sociabilidade frequentados pelo operariado funcionavam como uma espécie de ponto de convergência, em torno do qual se unificavam os interesses dos trabalhadores. Participar de bailes e festas populares animados pelo som das bandas operárias, frequentar bares e casas de jogos e apostas, promover refeições coletivas e reunir-se nas calçadas para "jogar conversa fora" estavam entre os principais costumes dos subalternos. As diferentes práticas de vida e lazer não apenas davam forma, conteúdo e amálgama ao operariado, como produziam o locus da constituição da identidade de seus integrantes. Eram a expressão simbólica e a materialização de um sentido concreto de comunidade, resultado das experiências sociais compartilhadas (PAOLI; DUARTE, 2004, p. 93).

Por todo o Brasil, desde o final do século XIX, os trabalhadores se reuniram por fábrica, por bairro, por categoria profissional, por nacionalidade e, mais tarde, por sindicato, para fazer música, dançar, comemorar datas significativas, etc. (DECCA, 1991, p. 66). 
Mas a conduta da classe trabalhadora também gerou reações adversas. Os meios operários foram se tornando objeto de profunda preocupação da burguesia industrial, que os enxergava como ambientes potencialmente perigosos para a moral e disciplina do trabalho, focos passíveis de agitação e revolta social. Com o desenvolvimento das formas de produção capitalistas, ampliou-se o preconceito em relação aos tradicionais hábitos da camada subalterna. Esta última teria uma "predileção pelos lazeres mais nocivos e mais degradantes porque é de uma espécie inferior, menos que humana, e sempre pervertida" (CORBIN, 1995, p. 369). Era preciso "moralizá-la", tornar os trabalhadores mais resistentes e submetê-los às exigências do novo sistema fabril.

\footnotetext{
A burguesia industrial interfere desde cedo nos rumos da formação da classe operária (...), incentiva a assimilação de práticas moralizadas e tenta adestrar os dominados para extrair o maior rendimento possível, acompanhando-os também nos momentos de não-trabalho (RAGO, 1985, p. 35).
}

Segundo os relatos de Moratelli (1996, p. 113), em meados de 1896, em uma casa próxima aos trilhos da Companhia Paulista, alguns indivíduos tinham o costume de se reunir para tocar instrumentos e "fazer música". Tal prática resultou na formação de uma sociedade musical - a Sociedade Musical União dos Artistas -, cujo grupo era composto por alguns operários da empresa ferroviária (Figura 2). O Jardim Público, situado no entorno da estação da Paulista, foi escolhido pelos membros da sociedade como ponto de concentração. Os ensaios e as apresentações a "céu aberto" tornavam-se mais constantes, expressavam os princípios da organização do operariado, um sinal evidente de que as ruas da cidade estavam se transformando em um palco de ações múltiplas dos sujeitos. 
Figura 2: Primeiros integrantes da Sociedade Musical União dos Artistas

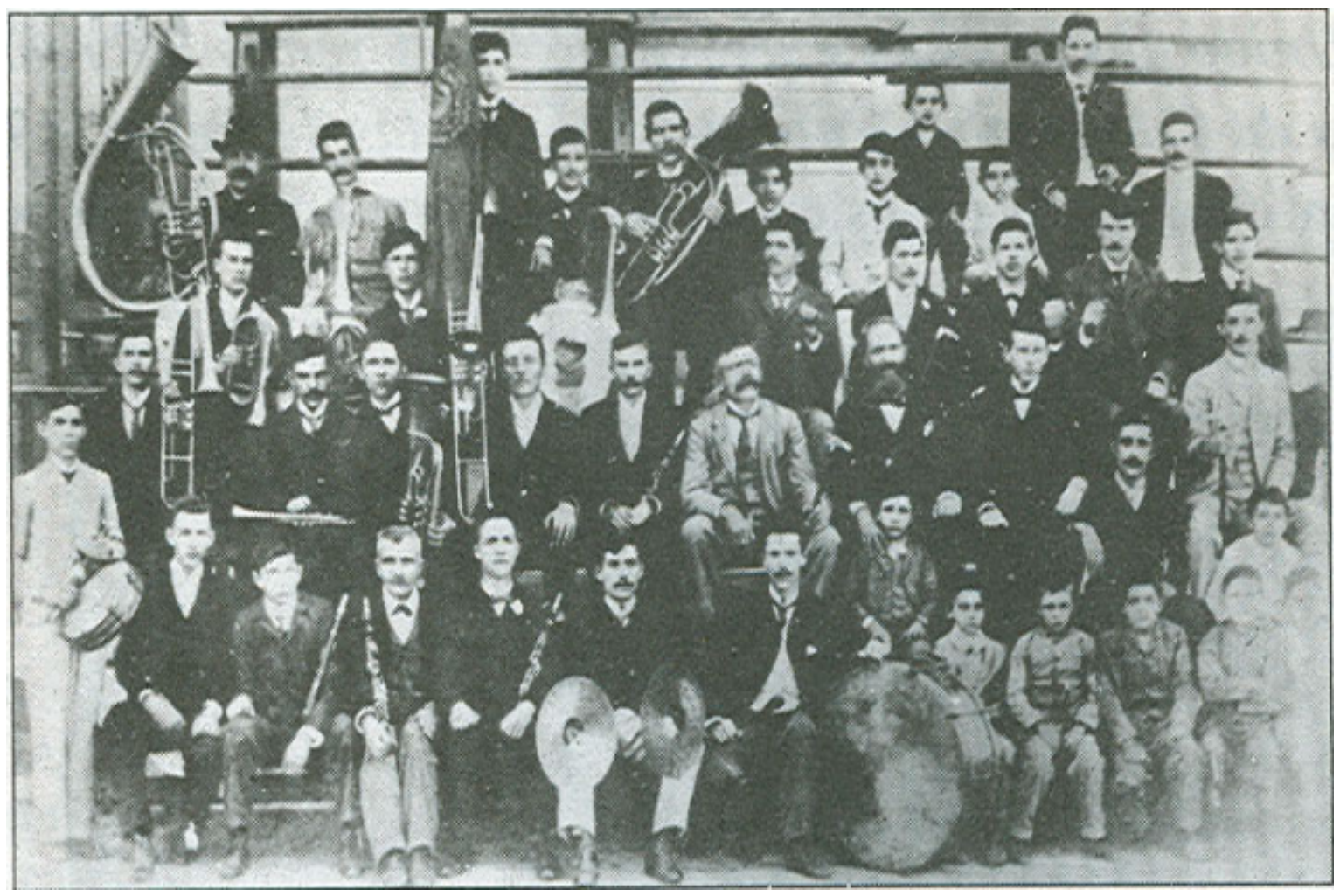

Fonte: Moratelli (1996, p. 44)

Contudo, a sociabilização operária não escapou ilesa das medidas reguladoras. No início do século XX, a administração da Companhia Paulista estabeleceu as primeiras intervenções sobre esses espaços de convivência coletiva, dando sinais de que o disciplinamento de sua mão-de-obra se estenderia para além dos muros da empresa. As iniciativas e associações que expressavam os interesses da classe operária foram absorvidas pela cúpula diretora, apropriadas e devolvidas reformisticamente sob a forma de "benefícios", isto é, o controle e a administração das mesmas foram retirados das mãos dos proletários "ignorantes" e repassados para a responsabilidade de seus superiores hierárquicos, em geral funcionários de confiança da companhia. Para os capitalistas, era de suma importância que todo um conjunto de encarregados do 
exercício da vigilância, como os mestres, contramestres, inspetores e fiscais estivessem integrados nestes círculos operários, pois isso possibilitaria a imposição de comportamentos padronizados, visando impedir a emergência da ação espontânea daqueles que eram considerados bárbaros, rudes e incivilizados (RAGO, 1985, p. 22).

A alteração do nome da sociedade musical para Grêmio Recreativo dos Empregados da Companhia Paulista, a nomeação do britânico Adão Gray - chefe local das oficinas - para presidir a entidade e a consequente ampliação da oferta de atividades para os ferroviários frequentarem durante o tempo livre, ilustram bem a modalidade de disciplinarização mencionada acima. A Figura 3 dá uma ideia da gerência patronal estabelecida sobre o grupo musical que havia sido idealizado inicialmente pelos subalternos. Enquanto os operários-músicos estão em pé, portando seus instrumentos, encontram-se sentados, na primeira fileira, os também britânicos William Holdship importante engenheiro da empresa ferroviária - e James Fernie - sub-chefe das oficinas e posteriormente superintendente. 
Figura 3: Grupo musical de operários mantido pela Companhia Paulista, 1900-1901. Sentados, na primeira fileira, William Holdship (o segundo da esquerda para a direita) e James Fernie (o quarto da esquerda para a direita)

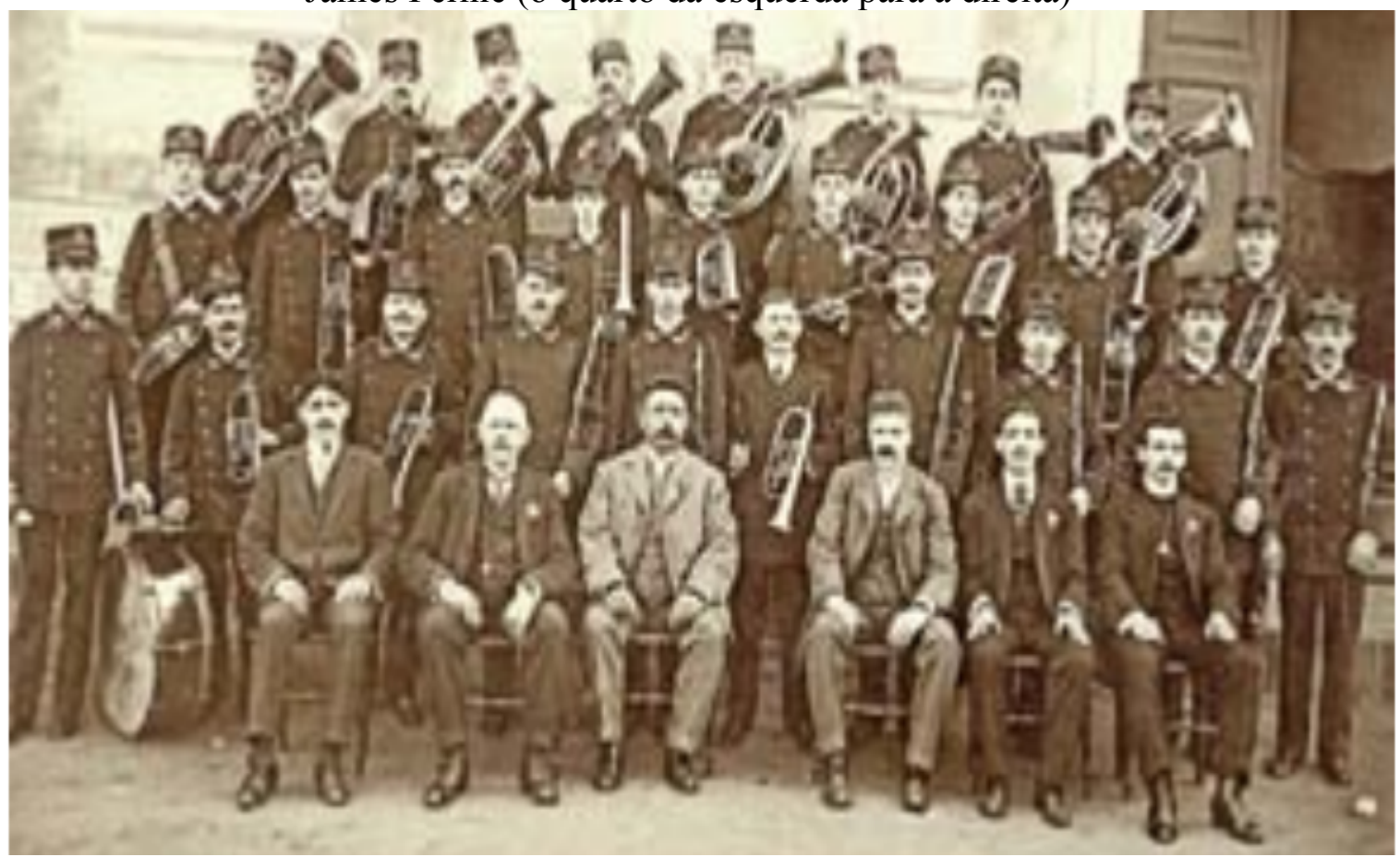

Fonte: Moratelli (1996, p. 43).

Amparado pela direção da Paulista, Adão Gray teve "carta branca" para coordenar todo o processo de implantação da infraestrutura do Grêmio, cuja sede foi instalada em 1910 em um terreno situado no bairro Santa Cruz, mais precisamente na Rua 9 (Fotografia 1). A administração geral da companhia manteve a propriedade em nome do próprio clube e ainda fornecia subsídios para o desenvolvimento de suas atividades. Em contrapartida, exigiu uma cláusula no estatuto da associação: em hipótese alguma o patrimônio do Grêmio poderia ser vendido sem a prévia autorização dos dirigentes da empresa ferroviária.

[...] A Companhia Paulista de Estradas de Ferro vai criando e recriando formas de controle que estarão permanentemente sob a vigilância da empresa. Essas entidades, principalmente as de lazer, são administradas pelos próprios ferroviários da oficina que necessariamente ocupam altos cargos na estrutura hierárquica da mesma, estando em acordo com os objetivos da empresa (GARCIA, 1992, p. 170). 
Salões de dança, campo de futebol, banda de música, aparelhos de ginástica, entre outros, compunham os equipamentos coletivos a disposição da classe trabalhadora. O estabelecimento da agremiação refletia um mecanismo de enquadramento do proletariado ao modelo disciplinar imaginado pela burguesia. $\mathrm{O}$ controle das horas livres do trabalhador pelos dominantes era uma forma de tentar impedir que cada um dispusesse livremente de seu próprio tempo,

[...] interrompendo os fluxos que podem levar a encontros indesejáveis, a conversas não controladas, a agrupamentos espontâneos, a... quem sabe! articulações conspiratórias, nessa paranoia do medo da aglomeração dos dominados que assusta os patrões (RAGO, 1985, p. 185).

Fotografia 1: Atual fachada do Grêmio Recreativo dos Empregados da Companhia Paulista de Estradas de Ferro, em Rio Claro-SP

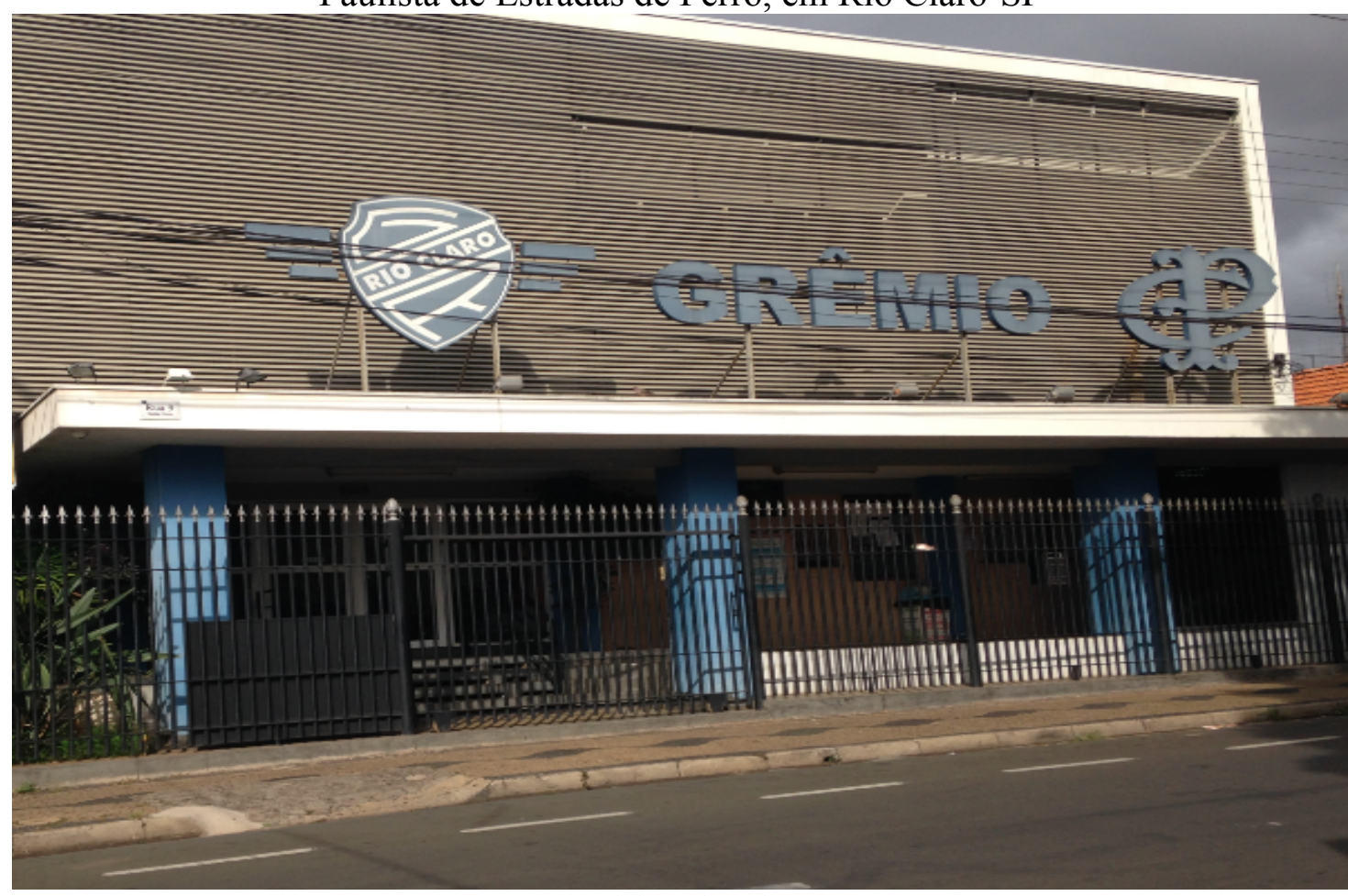

Fonte: Elaborada pelo autor

Assim, os ferroviários passaram a ser pressionados para se tornarem sócios do clube. Para viabilizar o objetivo de transmitir a ideia de aquele espaço de sociabilidade 
se destinava prioritariamente aos seus operários, a companhia ferroviária buscava facilitar a adesão da grande massa de subalternos. Estes últimos podiam associar-se em quantidade ilimitada, estavam isentos do pagamento de joia e as mensalidades apresentavam valores acessíveis. Era uma estratégia velada de controle, cuja intenção era criar nos trabalhadores um sentimento de orgulho em relação à empresa, uma harmonia entre ambos. Esperava-se difundir a sensação de que trabalhadores e patrões pertenciam a uma mesma "comunidade", lutando por interesses comuns (RAGO, 1985, p. 34).

O sonho patronal de moldar uma mão-de-obra obediente e cumpridora de seus deveres estendera-se às relações cotidianas da vida dos operários, aos seus momentos fora da esfera do trabalho, delimitando espaços cercados, fechados e supostamente adequados para estes frequentarem, de modo que estivessem "protegidos" dos riscos da contaminação moral das ruas agitadas e dos bares. Lá, podiam participar de bailes orquestrados, festas, jogar bilhar, sinuca, praticar modalidades esportivas e realizar cursos técnicos que eram ministrados por engenheiros da Paulista, cuja finalidade era o aumento da produtividade no cotidiano das oficinas, conforme demonstra o anúncio publicado no Almanach do Rio Claro, em 1906:

Nas horas de descanso e, para mostrar que o tempo é dinheiro, abriu a sociedade uma aula noturna, de Desenho, que é proficientemente dirigida pelo engenheiro da companhia Doutor Gabriel Penteado, cujo aproveitamento dos alunos já o está tornando saliente (KRETTLIS, 1906, p. 130).

As datas festivas também eram vistas pela Paulista como uma boa oportunidade para a construção de uma autoimagem paternalista. Nas comemorações referentes ao aniversário do Grêmio era comum a promoção de grandes piqueniques em cidades 
vizinhas, ficando a diretoria do clube responsável pela organização e distribuição dos comes e bebes, e sorteios de brindes e prêmios. Logo pela manhã, os ferroviários e seus familiares eram transportados em um trem especial cedido gratuitamente pela administração da companhia, regressando a Rio Claro somente no final da tarde. A transcrição abaixo, alusiva à organização do $18^{\circ}$ aniversário da agremiação, a ser comemorado em Americana, ajuda a ilustrar um pouco o modus operandi da Companhia Paulista no que diz respeito à construção de seu paternalismo.

Dia 15: Às 7 horas partirá desta cidade um trem especial gentilmente concedido gratuitamente pela Administração da Companhia Paulista, conduzindo à Villa Americana os sócios do Grêmio e suas excelentíssimas famílias, devendo regressar às 17 horas (GRÊMIO RECREATIVO DOS EMPREGADOS DA COMPANHIA PAULISTA DE ESTRADAS DE FERRO, 1914, p. 22).

Mas por trás dessas regalias concedidas aos ferroviários, funcionava um clube pautado em um modelo de organização e administração bastante excludente. Os candidatos interessados em ocupar algum cargo na diretoria estavam sujeitos, primeiramente, a uma espécie de "pente fino" dos dirigentes da Paulista. Após seus nomes serem estritamente avaliados, autorizava-se a abertura da votação para a escolha dos diretores, sendo o resultado final comunicado à alta cúpula da companhia, na qual se encontrava, por exemplo, o engenheiro mecânico chefe Durval de Azevedo, conforme demonstrado na transcrição subsequente. Os operários do "chão de fábrica", excluídos de qualquer possibilidade de candidatura, ficavam incumbidos de prestar assistência na conservação do espaço, sendo que as despesas com manutenção e pequenas reformas nas instalações eram pagas com as mensalidades dos associados.

[...] Ao sr. secretário, oficiar ao sr. Durval de Azevedo, engenheiro mecânico chefe da Companhia Paulista, cientificando-o do resultado da Assembleia Geral Ordinária da eleição de directoria, dos directores eleitos e votos que obtiveram, e o número de associados presentes, 
assim como anexar ao officio, uma cópia do balancete demonstrativo do movimento financeiro correspondente ao $2^{\circ}$ semestre, compreensível de março a agosto de 1930 (GRÊMIO RECREATIVO DOS EMPREGADOS DA COMPANHIA PAULISTA DE ESTRADAS DE FERRO, 1930, p. 3).

Em caso de reformas mais complexas ou ampliação da infraestrutura, a diretoria do Grêmio também recorria ao auxílio direto do quadro administrativo da empresa. Foi o que aconteceu, por exemplo, na década de 1920, quando o presidente Adão Gray apresentou aos demais sócios a proposta de construção de um novo salão nas dependências do clube, com o intuito de que o mesmo abrigasse bailes, teatro, cinema, patinação, entre outras atividades. O chefe local das oficinas encaminhou um ofício aos seus superiores, solicitando subsídios para o referido projeto. Os engenheiros Jayme Cintra e Francisco Paes Leme de Monlevade, chefe de locomoção e inspetor geral da companhia, respectivamente, aprovaram a execução da obra, orçada em pouco mais de cinquenta contos de réis. Para homenageá-los, a diretoria do Grêmio decidiu convidálos para a inauguração do salão e ainda fixar os retratos de ambos na sede social, uma forma evidente de demonstrar aos ferroviários a generosidade dos patrões.

[...] O sr. Roberto Ramalho pediu a palavra, propondo offerecer uma lembrança aos excelentíssimos srs. Drs. Francisco de Monlevade e Jayme Cintra, a colocação dos retratos de ambos, por exemplo, na sede social. O sr. presidente agradeceu a ideia do sr. Ramalho que vinha corroborar a resolução da diretoria tomada em sua última reunião, explicando que já se havia dado os passos necessários para inaugurar-se dia onze de abril próximo, os retratos daqueles digníssimos chefes (GRÊMIO RECREATIVO DOS EMPREGADOS DA COMPANHIA PAULISTA DE ESTRADAS DE FERRO, 1925, p. 47-48).

O ímpeto da Companhia Paulista em reger o lazer de seus operários era nítido. $\mathrm{Na}$ visão da cúpula administrativa, ao conceder certas "benevolências" para os subalternos, estes não teriam motivos para se mobilizar contra a empresa. Os 
ferroviários se sentiriam privilegiados, trabalhariam de forma cada vez mais intensa, não reclamando do emprego, e a empresa alcançaria os lucros desejados.

\section{Considerações Finais}

Como discutido, a chegada da ferrovia e a instalação das oficinas da Companhia Paulista de Estradas de Ferro em Rio Claro impulsionaram a formação da classe operária local. Claro. O convívio diário entre os ferroviários no universo fabril e o "vai e vem" destes trabalhadores nas ruas e bairros ao redor das linhas férreas propiciaram o surgimento de espaços de sociabilidade frequentados pelo operariado. O desfrute do lazer pelos ferroviários, além de proporcionar o distanciamento momentâneo da extenuante rotina de trabalho, forjava uma identidade cultural para o grupo, viabilizando novas bases emocionais de coesão e demarcando os territórios da classe trabalhadora.

No entanto, os ambientes e iniciativas que expressavam os interesses dos operários despertaram grande preocupação entre os patrões. Ao criar o Grêmio Recreativo da Paulista, a direção da empresa ferroviária revelava o desejo de reger o lazer de seus funcionários. A vigilância e o disciplinamento - já existente no interior das oficinas - estendia-se para os momentos de não-trabalho de seus funcionários. Conforme aponta Garcia (1992, p. 171), o cerco aos passos do trabalhador tornava-se mais consistente, sistemático e globalizante. Do ponto de vista do ferroviário, esse posicionamento da empresa em forma de ajuda poderia ser visto como um benefício prestado aos trabalhadores. Na prática, porém, constituía-se em uma forma de imobilização da mão-de-obra. Estabelecia-se uma espécie de "teia de favores", que gerava em contrapartida uma intensificação do controle sobre os operários. 


\section{REFERÊNCIAS}

ARQUIVO PÚBLICO DO ESTADO DE SÃO PAULO. Inventário de documentos do Fundo Secretaria dos Transportes: Departamento Ferroviário (1869-1971). São Paulo: Arquivo Público do Estado de São Paulo, 2015. 76 p.

BENÉVOLO, A. Introdução à história ferroviária do Brasil: estudo social, político e histórico. Recife: Folha da Manhã, 1953. 700 p.

CAMPOS, H. G. Caminhos da história: estradas reais e ferrovias. Belo Horizonte: Fino Traço, 2012. 168 p.

CORBIN, A. História dos tempos livres: o advento do lazer. Lisboa: Teorema, 1995. $514 \mathrm{p}$.

DECCA, Maria Auxiliadora Guzzo de. Indústria, trabalho e cotidiano: Brasil, 1880 a 1930. 10 ed. São Paulo: Atual, 1991. 95 p.

GARCIA, L. B. R. Rio Claro e as oficinas da Companhia Paulista de Estrada de Ferro: trabalho e vida operária, 1930-1940. 1992. 223 f. Tese (Doutorado) - Instituto de Filosofia e Ciências Humanas, Universidade Estadual de Campinas, Campinas, 1992.

GRÊMIO RECREATIVO DOS EMPREGADOS DA COMPANHIA PAULISTA DE ESTRADAS DE FERRO. Livro de Atas. Rio Claro, 15 ago. 1914, p. 22.

Livro de Atas. Rio Claro, 16 mar. 1925, p. 47-48.

Livro de Atas. Rio Claro, 10 set. 1930, p. 3.

KRETTLIS, C. Almanach do Rio Claro. Rio Claro: Typographia Conrado, 1906. 145 p.

LANNA, A. L. D. Trabalhadores das ferrovias: a Companhia Paulista de Estrada de Ferro, São Paulo, 1870-1920. Varia Historia, Belo Horizonte, v. 32, n. 59, p. 505-545, maio/ago. 2016. Disponível em: http://www.scielo.br/pdf/vh/v32n59/0104-8775-vh-3259-0505.pdf. Acesso em: 10 dez. 2016.

MORATELLI, J. Sociedade Musical "União dos Artistas Ferroviários": edição comemorativa 1896-1996 - centenário. Rio Claro: Arquivo Público e Histórico do Município de Rio Claro, 1996. 45 p.

PAOLI, M. C.; DUARTE, A. São Paulo no plural: espaço público e redes de sociabilidade. In: PORTA, P. (Org.). História da cidade de São Paulo: a cidade na primeira metade do século XX: 1890-1954. v. 3. São Paulo: Paz e Terra, 2004. p. 53100.

RAGO, M. Do cabaré ao lar: a utopia da cidade disciplinar: Brasil 1890-1930. 2. ed. Rio de Janeiro: Paz e Terra, 1985. 209 p. 
TENCA, A. Senhores dos trilhos: racionalização, trabalho e tempo livre nas narrativas de ex-alunos do curso de ferroviários da antiga Paulista. São Paulo: Editora Unesp, 2006. 332 p.

ZALUAR, A. A máquina e a revolta: as organizações populares e o significado da pobreza. São Paulo: Brasiliense, 1985. 265 p.

\section{Endereço dos Autores:}

Renan Vidal Mina

Rua Boaventura do Amaral, 987, Apto. 44 - Centro

Campinas - SP - 13015-191

Endereço Eletrônico: rvidalmina@gmail.com

Marco Antonio Bettine de Almeida

Universidade de São Paulo

Escola de Artes, Ciências e Humanidades

Rua Arlindo Bettio, 1000 - Vila Guaraciaba

São Paulo - SP - 03828-000

Endereço Eletrônico: marcobettine@gmail.com 